\title{
Multiscale Study of Bacterial Proliferation Modes within Novel E. coli@Si(HIPE) Hybrid Macrocellular Living Foams
}

\author{
Martin Depardieu, ${ }^{1,5, \dagger}$ Mélanie Viaud, ${ }^{1}$ Axel Buguin, ${ }^{2}$ Jacques Livage, $, 4,5$ \\ Clément Sanchez, ${ }^{3,4,5}$ and Rénal Backov ${ }^{1, *}$
}

${ }^{1}$ Université de Bordeaux, CRPP-UPR CNRS 8641116 Avenue Albert Schweitzer, 33600

Pessac, France.backov@crpp-bordeaux.cnrs.fr

${ }^{2}$ Université Pierre et Marie Curie (UPMC) Institut Curie, Laboratoire de Physico-chimie Curie, 26 rue d'Ulm, 75248 Paris Cedex 05, France

${ }^{3}$ Sorbonne Universités, UPMC Université Paris 06, UMR 7574, Chimie de la Matière Condensée de Paris, F-75005, Paris, France.

${ }^{4}$ CNRS, UMR 7574, Chimie de la Matière Condensée de Paris, F-75005, Paris, France.

${ }^{5}$ Collège de France, Chimie de la Matière Condensée de Paris, 11 place Marcelin Berthelot, 75231 Paris Cedex 05, France.

${ }^{\dagger}$ Present address: Max Planck Institute of Colloids and Interfaces, Potsdam-Golm Science Park, Am Mühlenberg 1 OT Golm 14476 Potsdam, Germany.

\begin{abstract}
For the first time the study at various length scales of E. coli proliferation modes within $\mathrm{Si}(\mathrm{HIPE})$ inorganic macrocellular foams is proposed. Both qualitatively and semiquantitatively, the bacterial proliferation within the foam is not homogeneous and is directly linked to the $\mathrm{Si}$ (HIPE)'s macroscopic cells random distribution. When inoculated in a nutrients loaded $\mathrm{Si}$ (HIPE), the bacterial growth is enhanced within the Si(HIPE) matrices compared to the surrounding LB media. The bacteria growth kinetics tends to be faster and the concentration at saturation is roughly $100 \%$ times higher. In the case of a Si(HIPE) host free of nutrients, the bacterial motion is occurring as an infiltration wave, the peak of this propagation wave moving at a constant speed of $88 \mu \mathrm{m} \mathrm{h}^{-1}$, while bacterial concentrations within the Si(HIPE) reach levels far above the ones reached with the presence of nutrients, suggesting a real synergetic relation between the bacterial colony guests and the Si(HIPE) host. When a nutrients reservoir is present at the opposite position from which bacteria were inoculated, the bacterial proliferation is associated to a coalescence process between the growing colonies that were rapidly established within the first hours. When the Si(HIPE) is fully colonized we found out a specific distance between adjacent colonies of 5 to $15 \mu \mathrm{m}$ in good correspondence with the repartition of the wall to wall distances of the Si(HIPE)'s macroscopic cells, meaning that the bacterial repartition once the colonization occurred is optimum. These results show that $\mathrm{Si}$ (HIPE) foams represent outstanding candidates for strengthened bacterial proliferation without the motion restriction imposed by conventional silica gels.
\end{abstract}




\section{TOC}

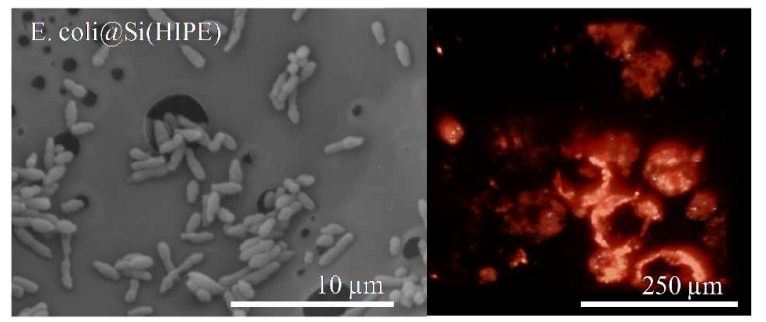

This multiscale study depicts the fundamentals of bacterial proliferation modes within hybrid E. coli@Si(HIPE) macrocellular living foams. 


\section{Introduction}

Biotechnological applications where guest living organisms are immobilized within a porous media is today of prominent interest for both industrial applications and academic research, from energy conversion or production and heterogeneous catalysis to pollutant degradation and so forth.$^{1-6}$ Bacteria can be encapsulated either into organic polymers ${ }^{7}$ or inorganic gels ${ }^{8,9}$ and among all the strategies to confine them, the sol-gel process is certainly one of the most promising path ${ }^{10,11}$ as it allows their confinement while maintaining both viability and metabolic acivity. ${ }^{12-14}$ Furthermore, those gels being transparent, biophotocatalytic applications can be addressed. ${ }^{15-18}$ Beyond this versatility, there are still some drawbacks to circumvent. The first are the weak intrinsic mechanical properties of those hybridized gels. This issue can be addressed quite easily, for instance by embedding the biogel into a surrounding canister, this canister being made of quartz if UV-light is needed. Unfortunately, the second main drawback cannot be circumvented with ease. It concerns the lack of free volume around the bacterial colonies, which does not allow their division and thus their proliferation. This is really damageable as a confined bacteria colony connected to a virtually infinite nutrients reservoir exhibits a behavior completely divergent to the one observed in traditional bacterial growth media. ${ }^{19-21}$ In this specific configuration the bacteria's divisions and associated proliferation are occurring until a lack of free volume is reached, and not because of bacterial chemical exchanges through Quorum sensing indicating a bacterial population threshold above which the proliferation and growth of bacterial population are stopped. ${ }^{19}$ A direct benefit of this peculiar phenomenon is that very high density of bacteria colony can be reached, far above the ones observed in traditional bacterial growth media. ${ }^{20,21}$ We believe that self-standing silica-based macrocellular monolithic foams are appearing as outstanding candidates to address the above mentioned drawbacks. In this view, concentrated emulsions can be used as soft templates to generate macroporosity, leading to the generation 
of "polyHIPE" polymeric foams, H.I.P.E. being the acronym for High internal Phase Emsulsion. $^{22,23}$ The first synthesis of macroporous silica monoliths was reported in 1998 through a combination of an oil/water concentrated emulsion and sol-gel processing. ${ }^{24}$ Further development was made by our group ${ }^{25-27}$ by synthesizing the Si(HIPE) series, which allow the tuning of the macroscopic voids diameters on demand. Later on, our group has pioneering the first Pickering-based silica foams, labeled Si(PHIPE)s, offering high monodispersity of both macroscopic void and connecting window diameters. ${ }^{28}$ The Si(HIPE) materials are bearing mechanical properties far above classical wet silica gel, ${ }^{25-27}$ and the macroporosity is providing a free volume high enough to allow bacterial proliferation while taking advantage of the confinement effects mentioned above. ${ }^{19-21}$ The associated pores and connecting windows diameters, within the micrometer range, should also permit bacterial growth and proliferation. ${ }^{29}$ These materials have already been employed as host for proteins leading to enzyme-based biocatalysts providing outstanding conversion yields, turn over numbers (TON) and turn over frequencies (TOF). ${ }^{30,31}$

We study here bacterial proliferation within the Si(HIPE) macrocellular media at various length scales under various configurations, with and without the addition of nutrients. We will see that the bacteria confinement within the Si(HIPE) strongly enhances bacterial proliferation and concentration compared to a traditional bacterial growth media. Beyond, when coupling kinetic and quantitative investigations of bacterial growth, we show that the proliferation is governed by a coalescence phenomenon providing macroscopically a proliferation mode occurring as a propagation wave, with a speed of around $90 \mu \mathrm{m} / \mathrm{h}$, seventy folds lower than the one observed in linear capillaries free of tortuosity.

\section{Experimental}

Si(HIPE) synthesis 
All reagents where obtained from Sigma Aldrich and used without further purification. Synthesis and full characterization of the Si(HIPE) porous silica host can be found in previous work. ${ }^{25}$ Typically, Tetraethoxy-orthosilicate (TEOS) $(5 \mathrm{~g})$ is added to an aqueous solution of tetradecyltrimethylammoniumbromide (TTAB) (16 g, 35 weight \%) previously acidified with $7 \mathrm{~g}$ of $\mathrm{HCl}$. Hydrolysis is occurring in the beaker and it ends when a monophasic medium is obtained. The oily phase, namely dodecane $(35 \mathrm{~g})$, is then emulsified drop by drop into the hydrophilic continuous phase using a mortar, and the emulsion is then allowed to condense for 1 week at room temperature in closed plastic molds. The as-synthesized monoliths are washed three times with a tetrahydrofuran (THF)/acetone mixture $(1: 1 \mathrm{v} / \mathrm{v})$ to extract the oily phase. Drying of the materials for a week at room temperature is followed by a thermal treatment at $650^{\circ} \mathrm{C}$ (heating rate of $2^{\circ} \mathrm{C} \min ^{-1}$ ) for $6 \mathrm{~h}$, with a $2 \mathrm{~h}$ step at $200^{\circ} \mathrm{C}$ to remove the remaining organic material. The sample is thereafter labeled $\mathrm{Si}(\mathrm{HIPE})$.

\section{Preparation of the Si(HIPE) porous silica hosts for bacterial colonization}

A Si(HIPE) sample is sterilized by placing it in an oven at $180^{\circ} \mathrm{C}$ for $1 \mathrm{~h} 30$. It is then put into a beaker containing a Luria-Bertani (LB) growth medium containing ampicillin $\left(10^{-4}\right.$ weight \%). This typical medium is composed of $10 \mathrm{~g}$ tryptone, $5 \mathrm{~g}$ yeast extract, and $10 \mathrm{~g}$ sodium chloride in one liter of water. Its $\mathrm{pH}$ is adjusted to 7 with sodium hydroxide, and then it is autoclaved for 25 minutes at $120^{\circ} \mathrm{C}$. The beaker is then put under a dynamic vacuum at 200mbar until effervescence from the air leaving the material has stopped. It is then left under a static vacuum for three days. When using a motility buffer, the same manipulations were performed but the LB medium was replaced by a buffer containing a $\mathrm{pH} 7.0$ potassium phosphate buffer, 0.1mM (Ethylenediaminetetraacetic acid) EDTA, 1mM L-Methionine and $10 \mathrm{mM}$ sodium lactate. This motility buffer allows the bacteria to live and swim but doesn't allow them to divide.

Colonization of the Si(HIPE) host by bacteria 
When not specified otherwise, the typical colonization experiment is done as follow. A Si(HIPE) sample that was impregnated with a LB growth medium and ampicillin as described previously is put into an erlen-meyer containing enough of the same medium to cover it. The bacteria are an E. Coli mCherry strain (RP437, pZE1R-mCherry), expressing a red fluorescent protein and displaying a resistance to ampicillin. They were cultivated in $20 \mathrm{~mL} \mathrm{LB}$ at $37^{\circ} \mathrm{C}$ and 200rpm, then from this culture, monitored by optical density until the bacteria are in the exponential growth phase $\left(\mathrm{OD}_{600}=0.5\right.$ for a concentration of about $5.10^{7}$ cells $\left./ \mathrm{mL}\right), 200 \mu \mathrm{L}$ are transferred into the Erlenmeyer containing the sample. It is then placed into an incubator at $37^{\circ} \mathrm{C}$ with an agitation at $200 \mathrm{rpm}$.

\section{Preparation of samples for scanning electron microscopy}

Biological samples need a preparation step to be observed under Scanning electron microscopy (SEM), as the vacuum and electron beam are extremely detrimental to them. The goal of these preparation steps is to fix the sample for the observation while avoiding as much as possible the introduction of artefacts. The samples are first rinsed rapidly with a Phosphatebuffered saline (PBS). This PBS contains a phosphate buffer at physiological $\mathrm{pH}$ and isotonic sodium chloride to avoid, as it would happen with pure water, osmotic problems that would lead to the swelling and the rupture of bacterial membranes. The second step involves a 5\% glutaraldehyde bath for $24 \mathrm{~h}$ at $4^{\circ} \mathrm{C}$ to fix the bacteria, as it bridges proteins and hence fixes the structures. The third step is a series of ethanol baths in growing concentrations $(20 \%$, $40 \%, 60 \%, 80 \%, 96 \%$ ) to dehydrate the sample, which resides in each bath during one hour. Finally, the sample is placed into two hexamethyldisilazane baths during two hours. The volatility of this compound allows for the sample to be dried in air without collapsing the biological structures. Each step is done as delicately as possible, without stirring, to minimize as far as it can be the introduction of observation artifacts.

\section{Optical microscopy observations}


Fluorescence stereomicroscopy on whole samples was performed with a Zeiss Axiozoom V16 equipped with a fluorescence module. Confocal microscopy was done on a Leica DMIRE2 confocal microscope. Tridimensional reconstructions where obtained with the imagery software Image Surfer. Fluorescence microscopy for kinetics studies was performed on a Zeiss Axiovert 200 inverted microscope. Scanning electron microscopy was performed on a HITACHI TM-1000. Samples were gold-palladium coated before observation.

\section{Results and discussion}

\section{The Si(HIPE) foams used as bacterial hosts}

The Si(HIPE) materials are bearing hierarchically organized porosity. ${ }^{25}$ The syntheses make the use of oil in water direct concentrated emulsion to create the macroposity (Fig. 1a and $1 b)$.
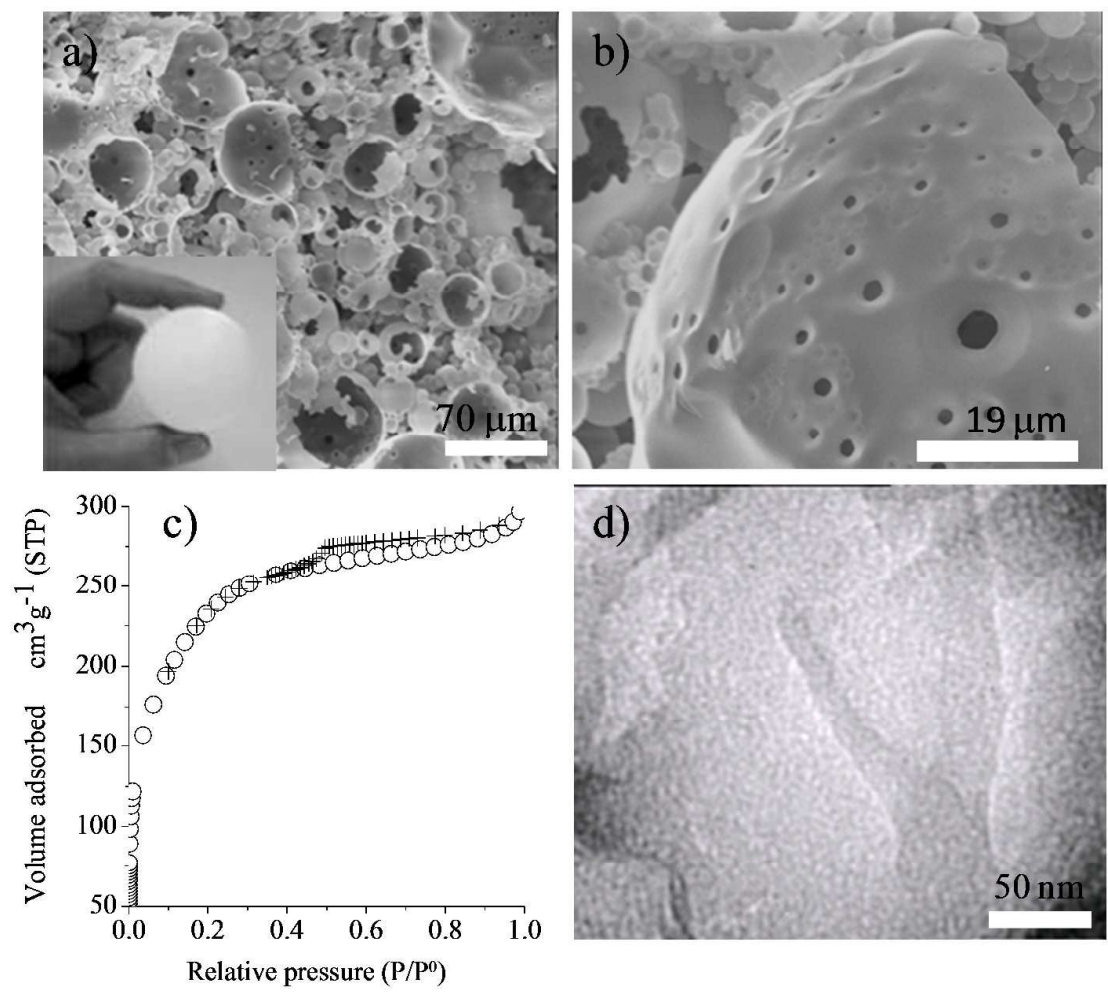

Figure 1. $\mathrm{Si}(\mathrm{HIPE})$ as porous hosts. a) and b) macroporosity observed through SEM, embedded $\mathrm{Si}$ (HIPE) self-standing monolith, c) Example of nitrogen physisorption experiments, $\bigcirc$ adsorption curve, + desorption curve, d) Transmission electron microscopy 
(TEM) visualization of the vermicular mesoporosity. Image reconstituted from the reference 15a, Copyright RSC.

Once sol-gel process has mineralized the continuous water phase and after THF washing and thermal treatment, the materials are self-standing (Fig. 1a embedded). Mercury porosity reveals that final materials are bearing 72 to $92 \%$ of porosity depending on the amount of starting oil volume fraction employed, $92 \%$ for the Si(HIPE) used in this study addressing $0.085 \mathrm{~g} \mathrm{~cm}^{-3}$ of bulk density and $0.98 \mathrm{~g} \mathrm{~cm}^{-3}$ of skeletal density. Tensioactive molecules are also employed to stabilize oil/water interface of the starting emulsions. As being far above the critical micellar concentration (CMC) within the aqueous continuous phase, this mesophase will create a vermicular type mesoporosity (Fig. 1d). Thereby these foams are also mesoporous inducing a hysteresis loop between nitrogen adsorption-desorption curves (Fig. 1c) while offering of $830 \mathrm{~m}^{2} \mathrm{~g}^{-1}$ of BET surface area, and $64 \mathrm{~m}^{2} \mathrm{~g}^{-1}$ of BJH mesoporous surface area. The strong nitrogen adsorption at low relative pressure (below 0.2) is the signature of strong microporosity of the materials, as the $\mathrm{SiO}_{4}$ tetrahedrals spatial repartition is random. Overall the $\mathrm{Si}(\mathrm{HIPE})$ foams are macro-, meso- and microporous bearing thus hierarchical porosity. The calcination treatment is also favoring the ceramic foams mechanical properties through the induced sintering. They are offering 0.1-0.3 GPa of Young modulus that allows the use of such foams under pressure as liquid chromatographic columns for continuous uni-axial enzyme-based heterogeneous catalysts, while minimizing the pressure drop. $^{30,31}$ On the contrary, they can also be use under strong vacuum without collapsing (0.2 mbar) when employed as sacrificial hard templates for the generation of Carbon(HIPE) foams with application toward energy conversion and storage. ${ }^{32}$

Considering the above mentioned Si(HIPE) morphological characteristics and their use as host for prokaryote development, the bacterial proliferation modes are studied within the following sections at various length scales both for qualitative and kinetic semiquantitative studies. At the macroscopic length scale, the investigations are conducted with 
the use of stereomicroscopy (from several centimeters to the sub-centimeter). Mesoscopic investigations (millimeter to the sub-millimeter) are addressed through confocal microscopy while studies at the microscopic length scale (micrometer range) make use of scanning electron microscopy.

Qualitative investigations at the macroscopic length scale

E coli@Si(HIPE) foams are macroscopically represented within the Figure 2 with and without the use of fluorescence imagery.
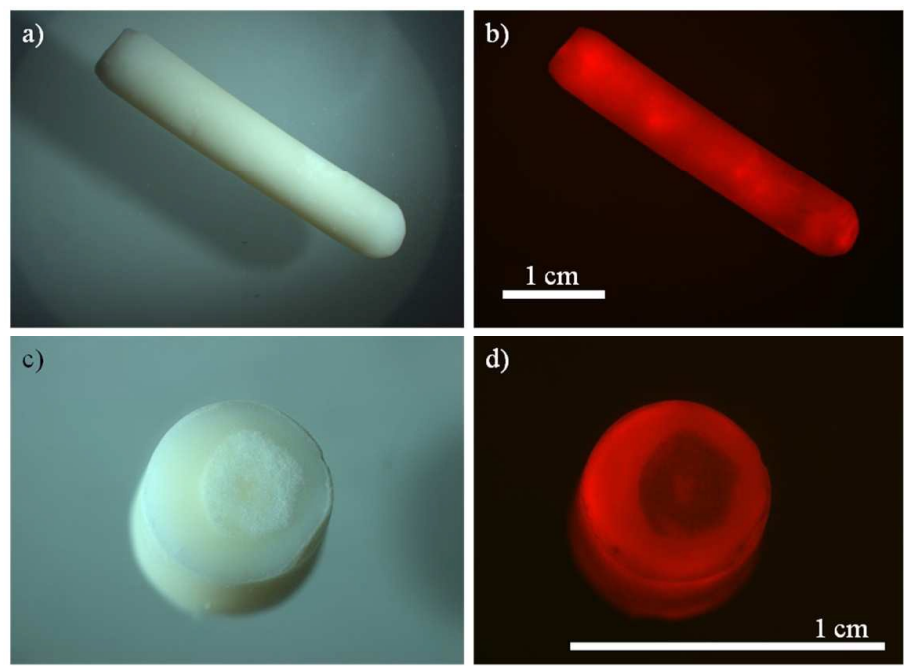

Figure 2. E. coli@Si(HIPE) monolithic foams observed either under polychromatic light or under monochromatic fluorescent conditions after a proliferation period time of 24 hours. a) hybrid foam observed under polychromatic light, b) same monolith when the bacterial fluorescence is observed, c) section of the monolith under polychromatic light, d) same section while observing the bacterial fluorescence.

At first glance when observing the sample (Figure 2a) or a section of it (Figure 2c) under polychromatic light, the material appears rather homogeneous and nothing allows to make the distinction with a bacteria free $\mathrm{Si}(\mathrm{HIPE})$. When observing the mCherry fluorescence in the same material (Figure 2b), we can see that some areas are emitting much more fluorescence than others, hinting at a certain inhomogeneity of the bacterial proliferation within the foam, certainly due to the presence of porous network defects randomly distributed in the whole monolith. Considering a foam section, the Figure $2 \mathrm{~d}$ demonstrates that the 
bacterial proliferation from the outer part into the foam core is only in progress at that stage and thus uncompleted.

Qualitative investigations at the mesocopic length scale through confocal microscopy

Confocal microscopy investigations at the millimeter scale (Figure 1S) reveal that when the foam's texture is homogeneous, the bacterial repartition is rather homogeneous too. When focusing further the confocal microscopy investigations at the millimeter scale and below, we can start to assess the bacterial repartition within the foam's macroscopic cells (Figure 3).
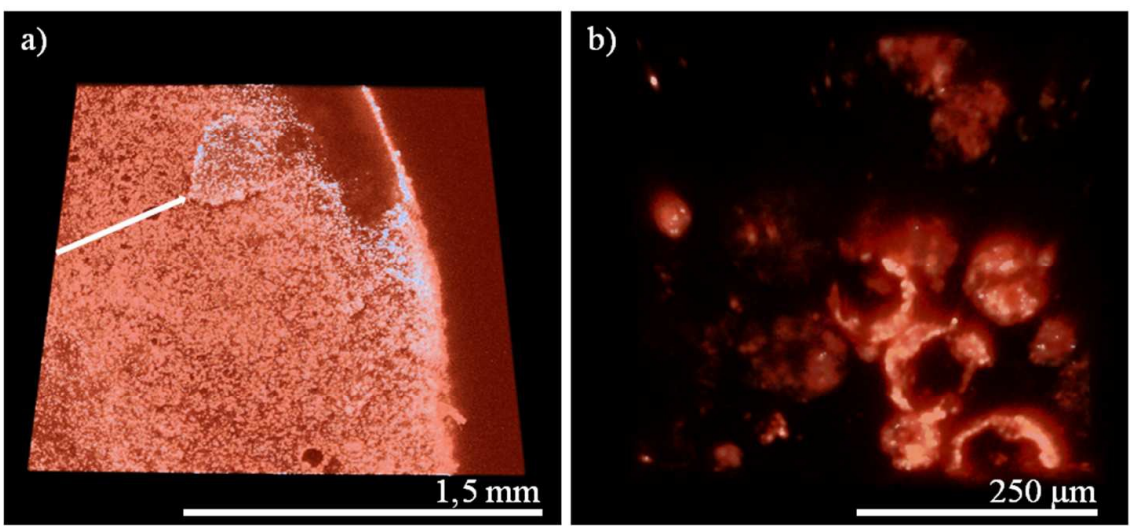

Figure 3. Confocal microscopy observations of an E. coli@Si(HIPE) Hybrid Macrocellular Foam after a proliferation period of 24 hours a) material bearing textural inhomogeneities inducing inhomogeneous bacterial repartition. The white arrow indicates a material fracture in which bacteria spread specifically, b) higher magnification where the bacterial repartition can be observed to follow the macroscopic cells' curvature.

On the Figure 3a a zone free of fluorescence (top right) can be seen indicating that on this area the porosity is not open, it is thereby free of any bacteria. On the contrary, a fracture containing a high bacterial concentration can be seen (white arrow), which illustrates once more the relation between the bacterial proliferation and the texture of the host material. Very interestingly, when increasing the magnification (Figure 3b), it can be observed that the bacterial colonies seem to accommodate the macroscopic cell's curvature and are specifically spread on the cell walls rather than in the macrocellular free volume. 
Qualitative Investigations at the microscopic length scale

The first microscopic qualitative investigation simply consists of visualizing the bacteria within the Si(HIPE) foams (Figure 4) through SEM. At first, we can easily recognize the typical $\mathrm{Si}(\mathrm{HIPE})$ macroscopic morphology consisting of aggregated hollow spheres bearing windows that connect adjacent cells. ${ }^{25-27}$
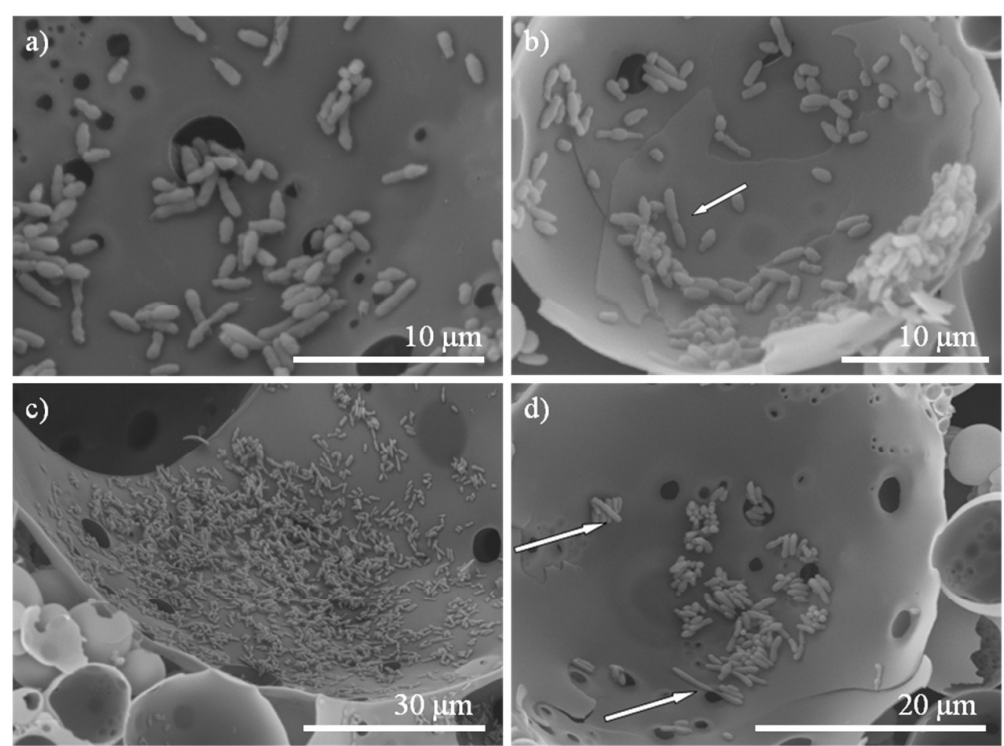

Figure 4. SEM observations of an E. coli@Si(HIPE) Hybrid Macrocellular Foam after a proliferation period of 24 hours. a) bacteria going through a window connecting adjacent macroscopic cells, b) bacteria within a macropore, the white arrow indicates a bacterial division, c) high bacterial concentration on a macropore wall's surface, d) bacterial colony bearing anomalously elongated bacteria, white arrows.

As depicted within the Figure 4a, the connecting windows allow the bacteria to spread into the $\mathrm{Si}(\mathrm{HIPE})$. At that microscopic scale we can conceive that each macropore is acting as a bioreactor in which bacterial growth occurs (Figure $4 \mathrm{~b}$ ) and then allows an easy exit of some bacteria through the connecting windows to colonize adjacent macroscopic voids (Figure 4a). We can also observe that some bacterial colonies present a very high population density (Figure 4c). All the bacterial colonies are observed on the macrocellular walls and one may think of an observation artifact caused by the drying occurring during the preparation of the sample for SEM observations. But when considering the confocal microscopy observations (Figure 3b), which is done in situ without any sample preparation, one can 
observe the same preferential bacterial proliferation on the macrocellular walls rather than in the cellular free volume. We can also distinguish elongated and undivided bacteria (Figure 4d, white arrows). This feature is typical of bacteria in a stressful environment, such as an external oxidative stress causing DNA damages, a need to increase the contact surface adhesion on a substrate, a lack of nutrients inducing a bacterial elongation to optimize nutrient transfer and so forth. ${ }^{33}$ The unusual bacterial growth conditions within the Si(HIPE) host are probably favoring this bacterial stress.

This first section dedicated to qualitative investigations provided two important informations. The first one is that $\mathrm{Si}(\mathrm{HIPE})$ foams can effectively be used as hosts for bacterial proliferation. The second one is that the bacteria's preferential localization is on the cellular walls rather than in the cells' free volume. We will now aim to study the bacterial proliferation kinetics and associated repartition of concentrations to assess more deeply their proliferation modes within the $\mathrm{Si}(\mathrm{HIPE})$. Again, these studies will be addressed at various length scales and under diverse nutrient conditions.

Kinetic and semi-quantitative investigations at the macroscopic length scale through fluorescence microscopy

Kinetic macroscopic investigations were done with inverted fluorescence microscopy (Figure 2S) under thermo-regulated conditions fixed at $37^{\circ} \mathrm{C}$. Depending on the experiment, the $\mathrm{Si}(\mathrm{HIPE})$ is either impregnated with an LB nutritive solution or a non-nutritive motility buffer. The solution of choice is put in a Petri dish until only two or three millimeters of the $\mathrm{Si}(\mathrm{HIPE})$ remain uncovered (Figure $2 \mathrm{~S}$ ). We varied the inoculation parameters in order to assess diverse bacteria proliferation modes into the $\mathrm{Si}(\mathrm{HIPE})$ host. Three configurations have been explored. For the first one, the Si(HIPE) already containing the LB nutritive medium is immerged within the same surrounding LB medium. The bacteria, taken from a culture in the exponential growth phase, are then inoculated into the surrounding LB medium. In the second 
configuration, the $\mathrm{Si}(\mathrm{HIPE})$, already impregnated with a LB medium, is added into a LB medium containing a bacterial colony in the exponential growth phase. During the third experiment, the $\mathrm{Si}(\mathrm{HIPE})$ is at first impregnated with a non nutritive motility buffer and then immerged into the same buffer containing bacteria in the same concentration as in a colony grown in LB until saturation.

Kinetic and semi-quantitative investigations at the macroscopic length scale: Si(HIPE) containing an LB medium immerged into the same nutritive medium where bacteria are then inoculated

Under this specific configuration we can clearly see a progressive increase of the fluorescence intensity with time in the Si(HIPE) (Figure 5 a-c).
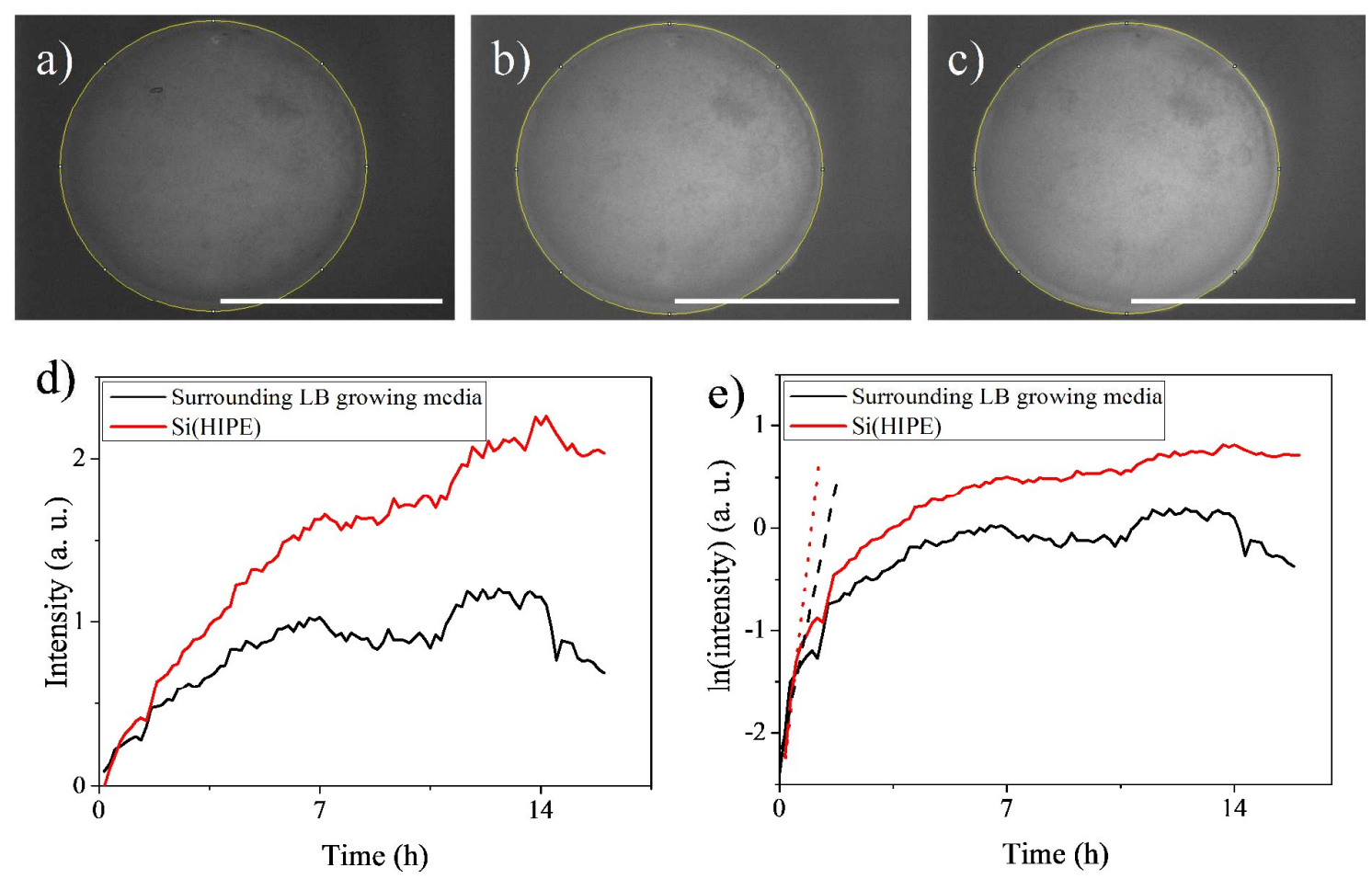

Figure 5. Fluorescence microscopy investigations. a-c) Examples of increasing fluorescence at various times, a) starting, b) 10 hours, c) 15 hours (the scale bars represent $5 \mathrm{~mm}$ ). d) Fluorescence intensities versus time in the $\mathrm{Si}$ (HIPE) and in the surrounding LB media, e) Logarithmic intensity values of (d). Curves d) and e) have been obtained though the "ImageJ" image treatment program. As silica is bearing intrinsic weak fluorescence, the first image is subtracted from the following ones. 
Considering the Figure $5 \mathrm{~d}$ it is obvious that bacterial growth and proliferation are strengthened within the $\mathrm{Si}(\mathrm{HIPE})$ compared to the surrounding LB medium. The kinetic of bacterial growth and associated concentration at saturation are roughly $100 \%$ higher in the case of the Si(HIPE) host compared to the surrounding LB medium. In both cases, no latency time is observed as the inoculated bacterial colonies were already in the exponential growth stage. Exploiting the fluorescence intensity logarithmic values, the exponential growth at the origin can be deduced from the linear evolution with time (Figure 5e, dotted lines). The slope at the origin allows obtaining the initial bacterial growth speeds. Here they are equal to $0.06 \pm$ $0.01 \mathrm{~h}^{-1}$ and $0.05 \pm 0.01 \mathrm{~h}^{-1}$ for the surrounding LB medium and the Si(HIPE) respectively. The doubling times, that corresponds to the duration time between two bacterial cells' division, are $13 \mathrm{~h} 50 \mathrm{mn}$ and $11 \mathrm{~h} 30 \mathrm{mn}$ respectively for the bacteria in the surrounding LB medium and the Si(HIPE) foam. Considering the bacterial colonies growth versus time within the $\operatorname{Si}($ HIPE) we can clearly see that the growth is inhomogeneous and depends on the bacterial colonies' position within the Si(HIPE), Figure 6.
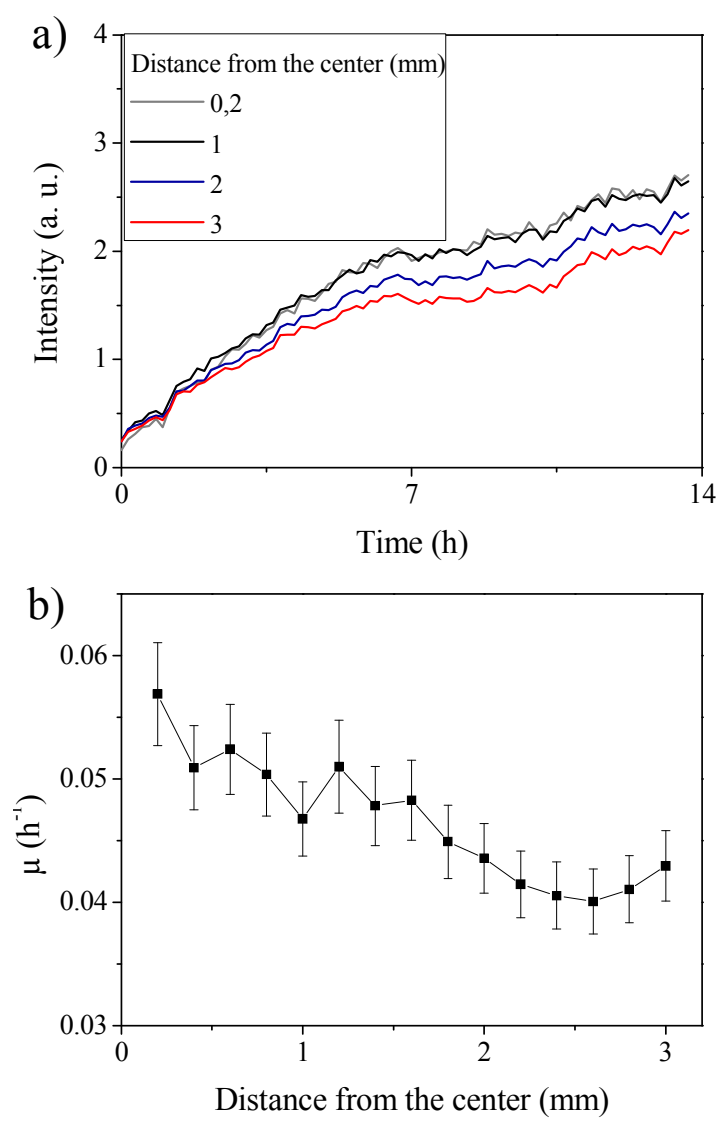
Figure 6. a) Fluorescence intensity profile at various distances from the Si(HIPE) monolith center, b) bacterial growth speeds at various positions from the Si(HIPE) monolith's center.

We can notice from the Figure 6a that the fluorescence's intensity grows as the position we look at is closer to the center of the monolith. The bacterial growth speed is also following the same trend with a higher growth speed at the Si(HIPE) monolith's center, with some edge effects (Figure 6b). The edge effects, at the interface between the monolith's external surface and the surrounding medium, are probably due to a weak bacterial diffusion/infiltration into the Si(HIPE) host, in addition to the intrinsic bacterial colonies proliferation and growth. Bacterial proliferation and growth seem indeed homogeneous in the whole monolith at the start of the experiment, then bacterial colonies close to the center of the monolith are growing faster than the ones present at the periphery. To explain this feature at that stage, we may hypothesize that the region close to the monolith center is offering an optimum between nutritive conditions and confinement effect. To explore these hypotheses we have changed the proliferation condition, and the $\mathrm{Si}(\mathrm{HIPE})$ is then emerged into an LB medium already containing bacterial colonies under exponential growth.

Kinetic and semi-quantitative investigations at the macroscopic length scale: Si(HIPE) containing an LB medium immerged into the same nutritive medium already containing bacterial colonies in the exponential growth phase.

Here again investigations are conducted through inverted fluorescence microscopy. The fluorescence intensity versus time profiles are provided within the Figures $7 \mathrm{a}$ and $7 \mathrm{~b}$. Contrary to what was observed in the first experiment, the differences in bacterial growth between the $\mathrm{Si}$ (HIPE) and the surrounding LB media are rather weak (Fig. 7a). The growth speeds during the exponential growth stand at $0.85 \pm 0.11 \mathrm{~h}^{-1}$ and $0.86 \pm 0.12 \mathrm{~h}^{-1}$ respectively for the surrounding LB media and the Si(HIPE), providing thus an overall generation time of 48 
minutes (Fig.7b). It means that the bacterial colonies' growth kinetic is much higher under this configuration than in the previous configuration where bacteria where inoculated. Thereby, the intensity of the fluorescence is also much higher than previously (Figures 5a and $5 b)$, three times higher for the surrounding media and almost two times for the Si(HIPE). This configuration definitively shows that the $\mathrm{Si}(\mathrm{HIPE})$ is favoring the bacterial proliferation. The $\mathrm{Si}(\mathrm{HIPE})$ is immersed into a LB medium where bacterial colonies are already under an exponential growth phase, and despite the $\mathrm{Si}(\mathrm{HIPE})$ porous-based tortuosity, there is practically no difference of bacterial colonies growth between the $\mathrm{Si}(\mathrm{HIPE})$ and the surrounding LB media. Also, when compared with a classical LB-based growing solution, the concentration reached within the $\mathrm{Si}(\mathrm{HIPE})$ is almost four times higher.
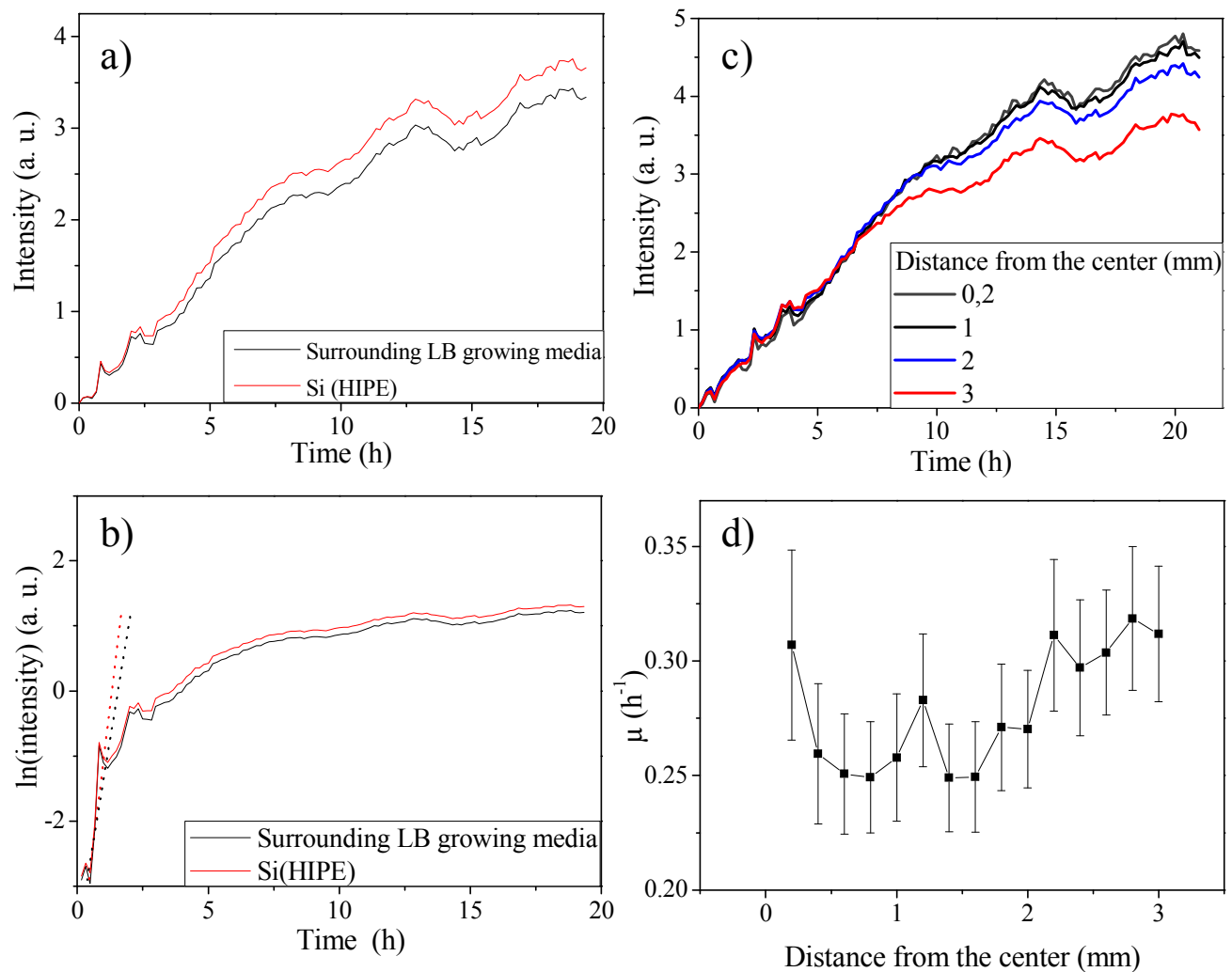

Figure 7. Fluorescence microscopy investigations. a) Fluorescence intensities versus time considering the Si(HIPE) and the surrounding LB growing medium, b) logarithmic intensity values of (a). Curves have been obtained though the "ImageJ" image treatment program. As silica is bearing intrinsic weak fluorescence, the first image is subtracted from the following ones, c) fluorescence intensity profile at various distances from the Si(HIPE) monolith's center, d) bacterial growth speed at various positions from the Si(HIPE) monolith's center. 
At that stage, we do not have a clear hypothesis concerning the dominant parameters that govern the bacterial growth and proliferation : bacteria confinements within a high surface area monolith, presence of nutrients, that may act cooperatively. Nevertheless, when considering these results and the Figures $3 \mathrm{~b}$ and 4, the presence of interfaces/walls seems to be very important. When taking into account the position of the bacterial colonies and the associated kinetics of growth (Figure 7c), they are respectively higher and faster when looking closer to the center of the monolith. When considering the bacterial growth speed versus the position into the $\mathrm{Si}(\mathrm{HIPE})$ (Figure $7 \mathrm{~d}$ ), the profile is almost reverse to what was observed for the first set-up based on bacteria inoculation (Figure 6b). In the present set-up bacteria are already present being at the exponential growth stage, meaning that on the edge, as before but enhanced this time, bacteria proliferation and enhanced bacteria diffusion are occurring additively.

Nutrients free kinetic and semi-quantitative investigations at the macroscopic length scale : Si(HIPE) infiltrated with a buffer motility medium immerged into the same medium containing bacterial colonies at the saturation concentration.

As we are now using a buffered motility medium, bacterial proliferation and growth won't happen, even though the bacteria can still live and swim. We can see with the figures $8 \mathrm{a}$ and $8 \mathrm{~b}$ that the fluorescence intensity profile within the surrounding buffer solution is almost flat while it is far from being the case in the $\mathrm{Si}(\mathrm{HIPE})$. This feature shows that, even in conditions free of nutrients, the affinity of the bacteria for the Si(HIPE) host is real. Thereby, if the presence of nutrients within the $\mathrm{Si}(\mathrm{HIPE})$ is a factor of primary importance for bacterial proliferation and growth, it is not a sine qua non parameter for bacterial infiltration/diffusion into the macrocellular host. Of course as there is no proliferation or growth in such conditions, we cannot extract a real bacterial proliferation speed, we will in that case rather use the term of "infiltration speed". We would like to underline that we do not use the term "diffusion 
speed" on purpose, because it is well know that bacteria can swim, ${ }^{34}$ thereby their motion is not driven only by a concentration gradient. When comparing this infiltration speed with the previous one of $0.86 \pm 0.12 \mathrm{~h}^{-1}$ obtained with bacterial colonies during their exponential growth phase, we can state that a non negligible part of the growth speed is coming from an infiltration phenomenon. Also, when compared with the first experiment (Figures. 5a and 5b), we can see that the fluorescence intensity within the HIPE is now three times and a half higher (Fig. 8c and 8a) while being constant in the whole material (Fig. 8d).
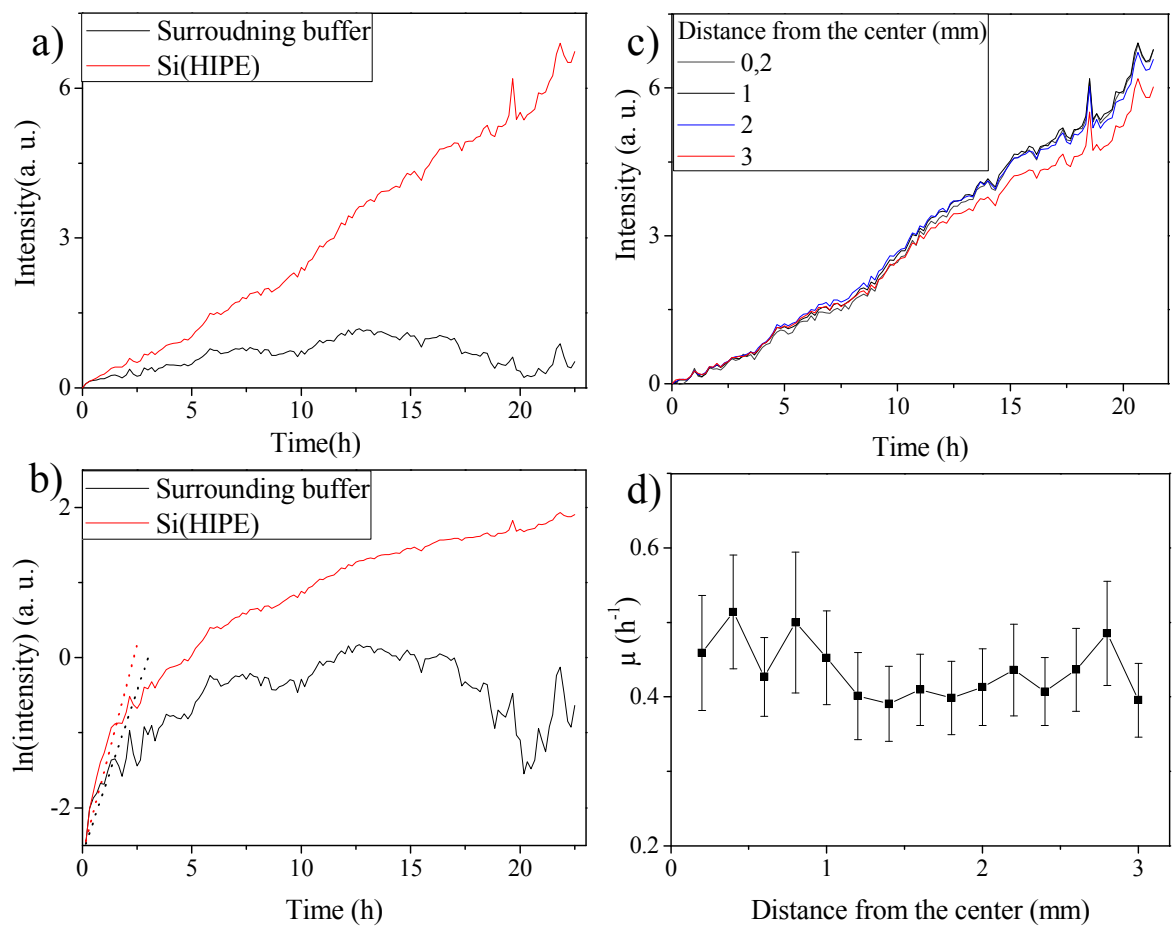

e)

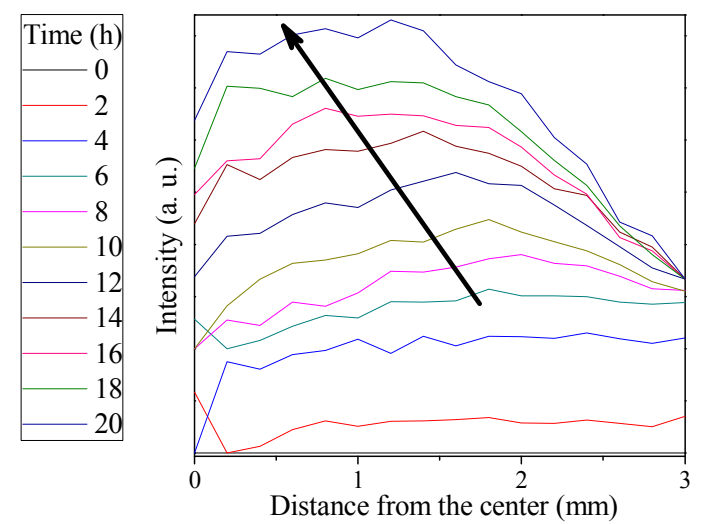

Figure 8. Fluorescence microscopy investigations. a) Fluorescence intensities versus time considering the $\mathrm{Si}(\mathrm{HIPE})$ and the surrounding buffered media, b) logarithmic intensity values 
of (a). Curves have been obtained though the "ImageJ" image treatment program. As silica is bearing intrinsic weak fluorescence, the first image is subtracted from the following ones. c) Fluorescence intensity profile at various distances from the Si(HIPE) monolith's center, d) bacterial infiltration speed at various positions from the Si(HIPE) monolith's center, e) evolution of the fluorescence intensity profile within the Si(HIPE) at different point in time.

We have doubt that this discrepancy of fluorescence intensity is induced only through a diffusive phenomenon, as the bacteria are certainly swimming actively to search for a confinement within the $\mathrm{Si}(\mathrm{HIPE})$ while offering a bacterial concentration six times higher than the one observed in the surrounding medium, that contained at the beginning of the experiment a bacterial concentration corresponding to saturation in a LB growth medium. What is really amazing is that without nutrients, bacterial concentrations within the Si(HIPE) reach levels far above the ones reached in the presence of nutrients. In this nutrients free survival conditions there is a real synergetic scenario between the bacterial colonies guests and the Si(HIPE) host. The figure $8 \mathrm{e}$ confirms that the bacteria are moving into the center of the Si(HIPE), particularly during the second half of the experiment. We can notice a wave of infiltration, the peak of this wave moving at a constant speed of $88 \mu \mathrm{m} \mathrm{h}^{-1}$. This phenomenon is well known by biophysicists when dealing with bacterial motion within unidirectional capillaries. ${ }^{35,36}$ Under these specific conditions the speed of the propagation wave was around $6.5 \mathrm{~mm} \mathrm{~h}^{-1}$, this to say 70 times faster than in a Si(HIPE); it appear thus that the foams porosity, more precisely the associated tortuosity, is considerably lowering the bacterial speed motion. Nevertheless this propagating wave exists in the Si(HIPE) foams acting as bacterial hosts and we provide the demonstration that bacteria are capable of swimming from the outer part of the Si(HIPE) to its center, when imposing nutrients-free survival conditions.

Kinetic and semi-quantitative investigations at the mesocopic length scale through confocal microscopy

These experiments are done with and without nutrients present within a specific reservoir to which the $\mathrm{Si}(\mathrm{HIPE})$ porous hosts, shaped as elongated rods, are connected (Figure 
3S). Confocal microscopy acquisitions are performed and then assembled to generate a whole view at the mesoscopic length scale.

Kinetic and semi-quantitative investigations at the mesoscopic length scale through confocal microscopy : no nutrients in reservoir

When no nutrients are present in the reservoir, other than those already present within the LB growth medium that is contained into the $\mathrm{Si}(\mathrm{HIPE})$, the bacterial proliferation is rather weak (Figure 9). After 24 hours (Fig. 9a) bacteria are present within the whole Si(HIPE) rod, but dense bacterial colonies are present only within the first $2 \mathrm{~mm}$. These colonies are growing during 4-5 days inducing higher fluorescence density within the $\mathrm{Si}$ (HIPE) (Fig. 9b). Rapidly, after one week, the bacterial densities within the Si(HIPE) are decreasing and some colonies seem to have completely vanished (Fig. 9c).
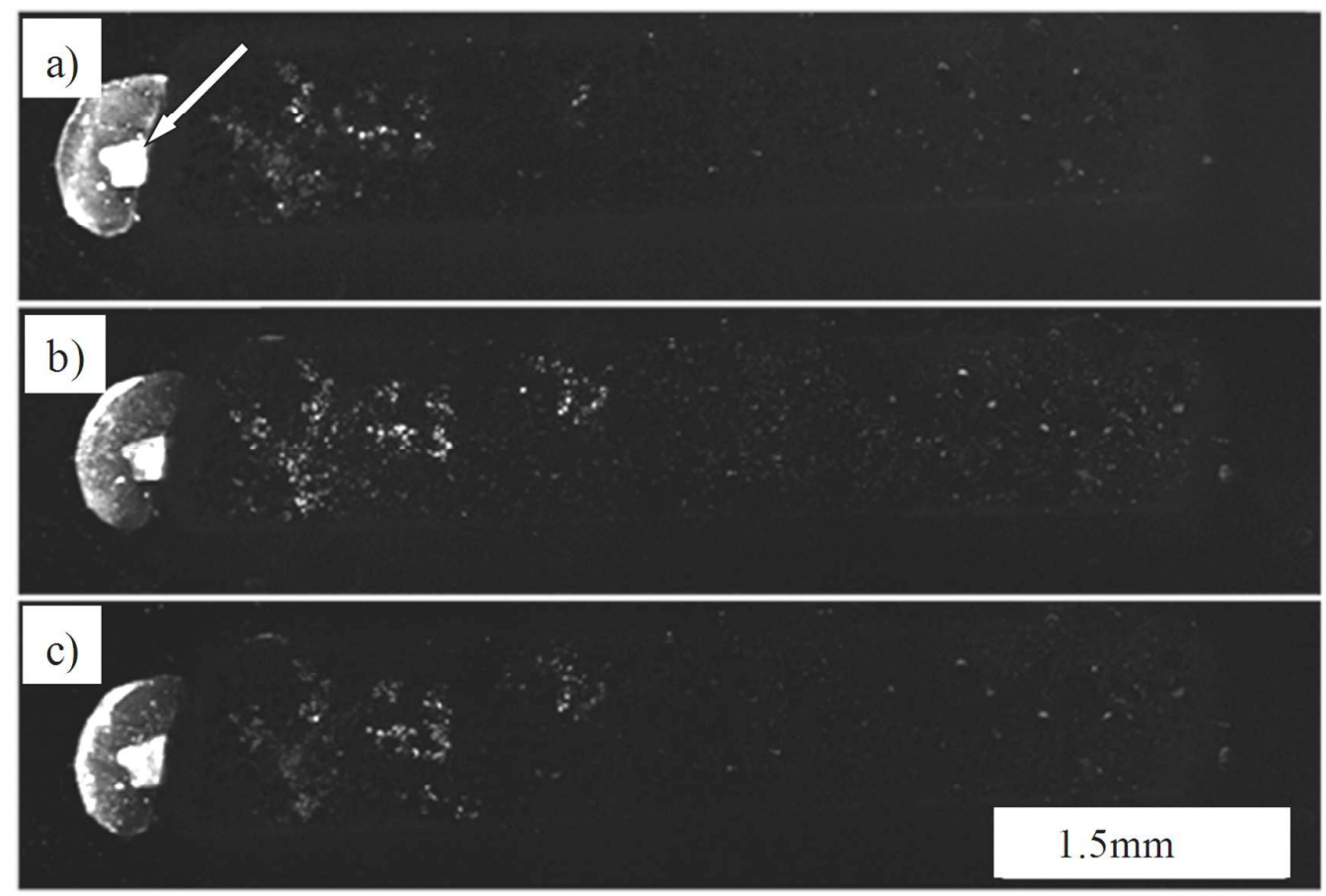

Figure 9. Sequenced images using confocal microscopy over a whole Si(HIPE) rod. The bacteria are deposited on the left extremity (white arrow) and are associated with a strong fluorescence. a) one day of proliferation, b) five days and c) eight days. No nutrients reservoir on right side. 
Without an external source of nutrients, bacterial colonies' proliferation decreases rapidly, as the nutrients concentration in the LB growth medium present within the Si(HIPE) is not high enough to sustain continuous growth of the colonies over several days.

Kinetic and semi-quantitative investigations at the mesoscopic length scale through confocal microscopy : nutrients in reservoir

Considering the Figure $10(\mathrm{~b}, \mathrm{c})$ bacterial proliferation is weak but present even during the first hours of experiments. Contrary to the previous experiment (Fig. 9a), colonies occupy the whole Si(HIPE) rod after 24 hours (Fig. 10d).

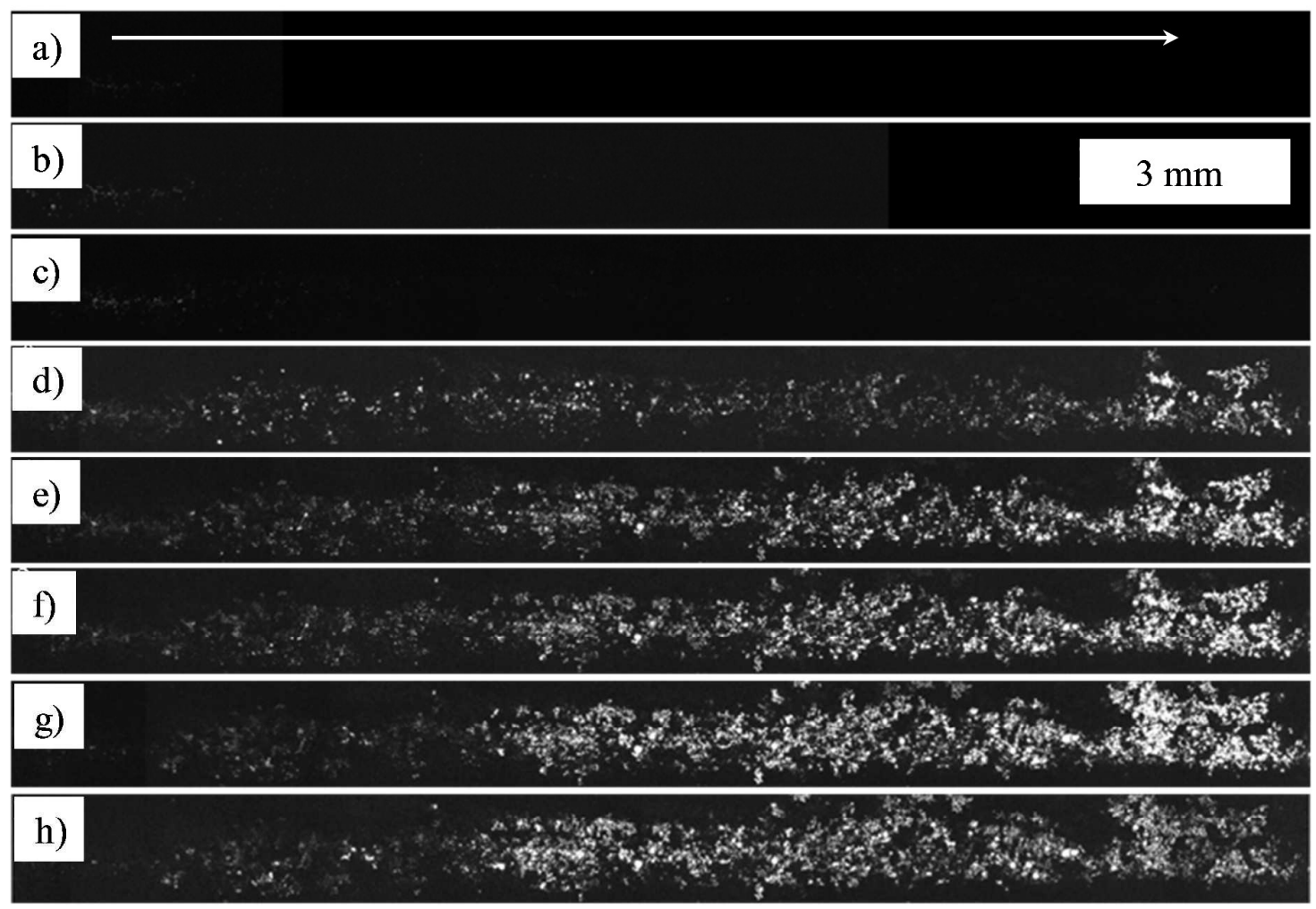

Figure 10. Bacterial growth and proliferation within a $\mathrm{Si}(\mathrm{HIPE})$ rod observed through confocal microscopy at different times. The white arrow indicates the direction of propagation. The bacteria are inoculated on the left while the nutrients reservoir is on the right. a) initial time, b) 3 hours, c) 10 hours, d) 1 day, e) 2 days, f) 3 days, g) 1 week h) 2 weeks. 
We can see that the fluorescence is increasing further during the following days and up to one week (Fig. 10d-g). During this period of time the fluorescence intensity is increasing but not the number of spots, meaning that colonies are growing without novel emerging colonies. Once the bacterial colonies occupy all the accessible porosity during the first colonization phase their migration stops. This means, as during the observation at the macroscopic length scale, that at the mesoscopic length scale the Si(HIPE) porosity and morphology are imposing the bacterial spatial repartition. After two weeks (Fig. 10h) the fluorescence is decreasing indicating a decrease of the bacteria numbers within the colonies, certainly induced with the Quorum sensing-based expression of metabolites that inhibit the growth and renewing of colonies. Beyond these observations, it is possible to plot the percentage of bacterial spatial spreading along the whole Si(HIPE) rod with time, as well as the number of colonies versus time (Figure 11).
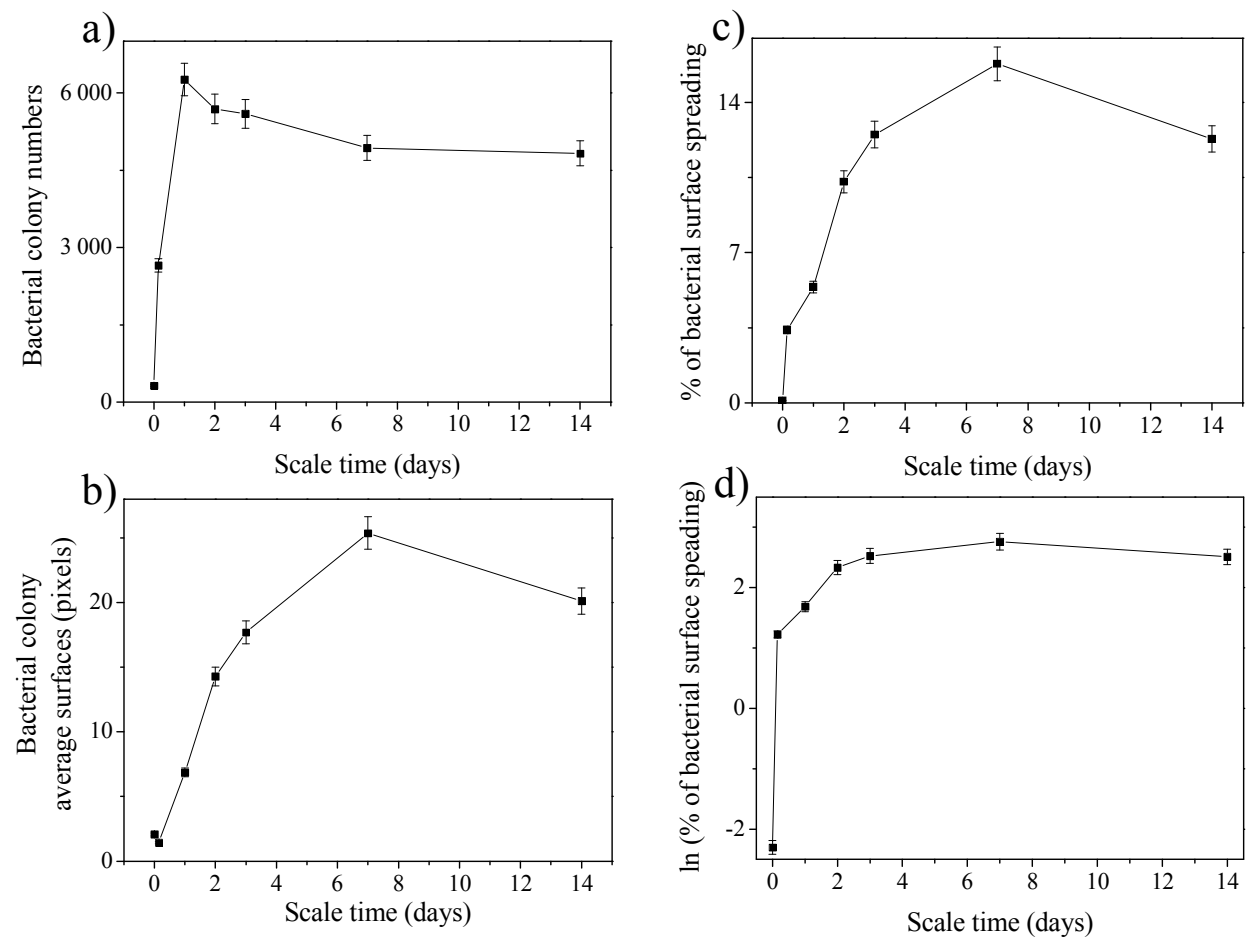

Figure 11. Semi quantitative investigations using confocal microscopy and the "Icy" image treatment software. a) Number of detected colonies versus time, b) average colonies' surface versus time, c) percentage of bacterial surface spreading versus time, d) ln values of (c). 
When considering the figure $11 \mathrm{a}$ we can notice that the maximum number of bacterial colonies is reached very rapidly within the first 24 hours, as already addressed with the Figure 9, and then their numbers start to diminish. The Figure $11 \mathrm{~b}$ shows that the volume occupied by bacteria growth over several days to reach a maximum around one week. Overall, one can deduce from Figure 10, Figures 11a and $11 \mathrm{~b}$ that the whole bacterial proliferation process within the first two weeks is nothing but a coalescence process between the growing colonies that were rapidly established within the first hours. Thereby, on the one hand the obtained growth curve (Fig. 11c) is indeed classical for growing bacterial colonies. On the other hand, the time scale is rather extended and the plateau of maximum bacterial density is reached after 3 to 4 days, while being traditionally reached within only few hours (Figure S4). ${ }^{37}$ This longer process is more clearly seen when considering the Figure 11d.

After having depicted the proliferation kinetics and modes within the Si(HIPE) the remaining question is if the final repartition is completely random or is following a certain distance distribution. We thus have evaluated the distances between adjacent colonies versus time, the results are provided within the Figure 12.
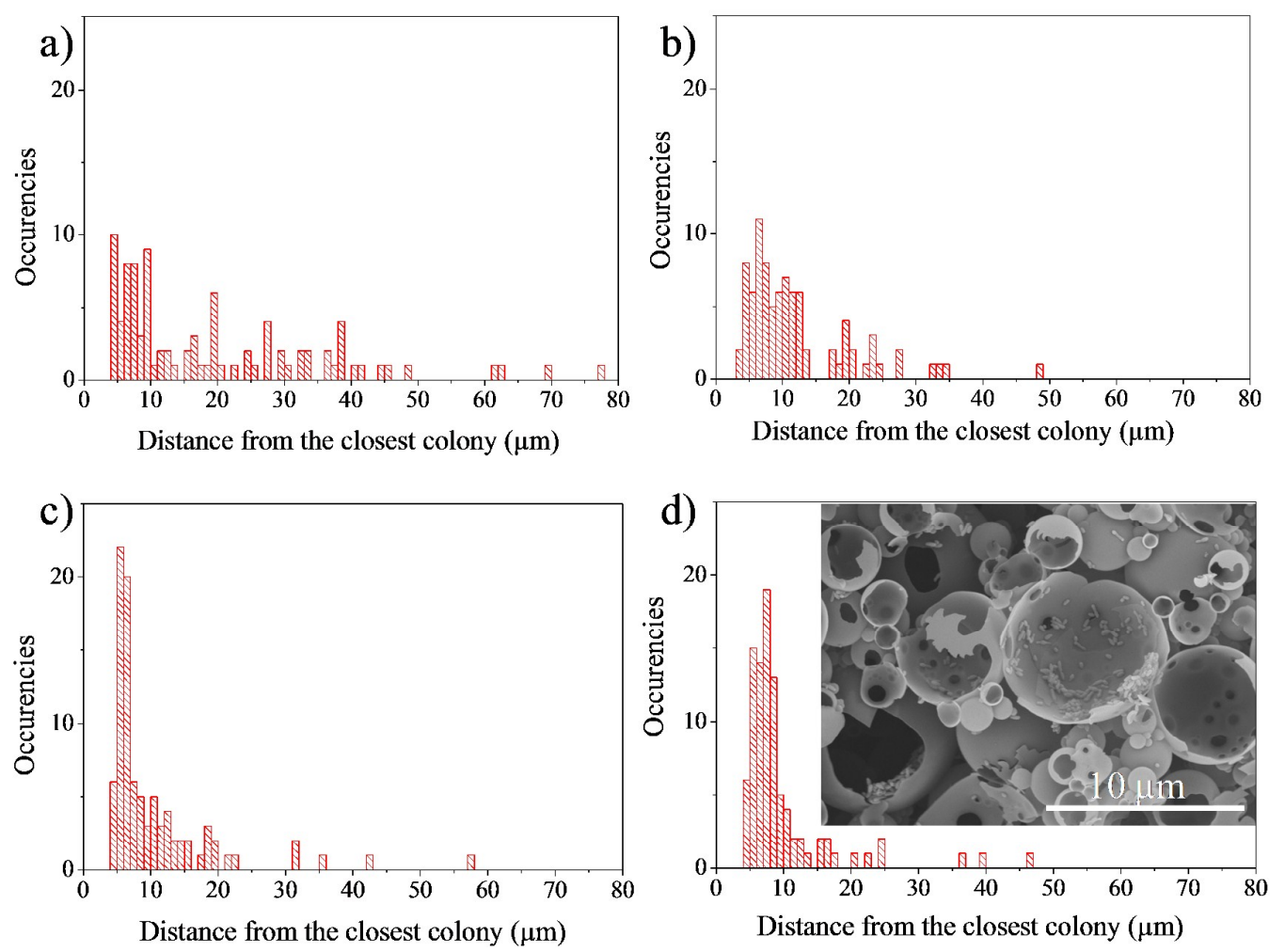
Figure 12. Distribution from the closest bacterial colonies versus time, a) 3 hours, b) 10 hours, c) 24 hours, d) 3 days. The embedded picture represents a SEM image of a Si(HIPE) after one day of bacterial growth.

When starting the experiment (Figure 12a) the distances between adjacent colonies are rather spread, ranging from 5 to $50 \mu \mathrm{m}$ for the main occurrences. After 10 hours of growth we can see that the distance between closest colonies is already squeezed from 5 to $25 \mu \mathrm{m}$ (Fig. 12b). At the 24 hours mark the distances between adjacent colonies are further squeezed between 5 to $15 \mu \mathrm{m}$ (Fig. 12c) $\mu \mathrm{m}$ and remain so after (Fig. 12d). These results are in good correlation with the previous ones (Figures 10 and 11), where we have first an increase of the bacterial colonies' numbers and secondly their growth, feature that intrinsically diminishes the distance from one growing bacterial colony to the other. When considering the Si(HIPE) macroscopic cells (Figure 12d, embedded), we can easily notice that this separation distance of closest bacterial colonies at 5-15 $\mu \mathrm{m}$ and the $\mathrm{Si}(\mathrm{HIPE})$ wall to wall distance are in good agreement. The distance of 5-15 $\mu \mathrm{m}$ is the one expected for bacterial colonies present on wall surfaces of $\mathrm{Si}(\mathrm{HIPE})$ adjacent macroscopic cells. These observations confirm thus that the whole accessible porosity is filled by the bacterial colonies.

In order to complete these investigations we made use of SEM to provide informations at the microscopic length scale. With the SEM investigations bacteria will be distinguishable individually, which was not possible with optical microscopy.

Kinetics and semi-quantitative investigations at the microscopic length scale through scanning electron microscopy

SEM investigations and associated distributions of bacterial populations with time are summarized within the Figure 13. As the SEM resolution allows to distinguish individual bacteria we arbitrarily subdivided the population into four categories : isolated bacteria, bacterial colonies bearing less than ten members, bacterial colonies bearing between ten and 
twenty members, between twenty and fifty, and finally bacterial colonies bearing more than fifty bacteria. In the first hours (Figures 13a-b, embedded) bacteria start their division and spreading within the whole $\mathrm{Si}(\mathrm{HIPE})$ macroscopic voids. At that stage, the evolution of the bacterial population's density is thus based on isolated bacteria, starting their divisions, that result in the formation of small colonies (Figure $13 \mathrm{a}$ and $\mathrm{b}$ ).

a)

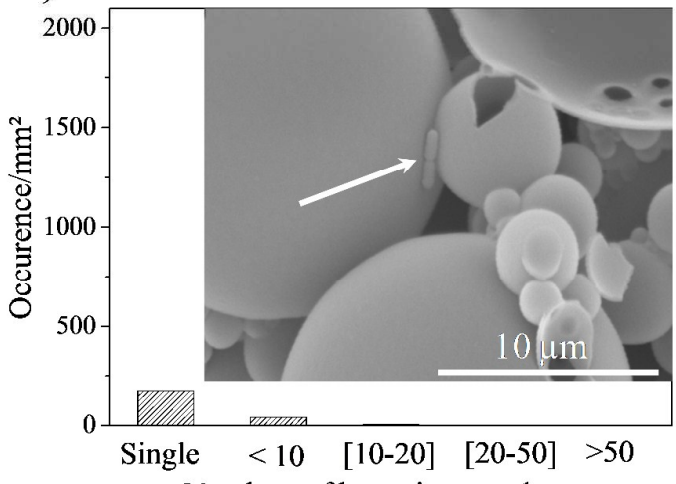

c)
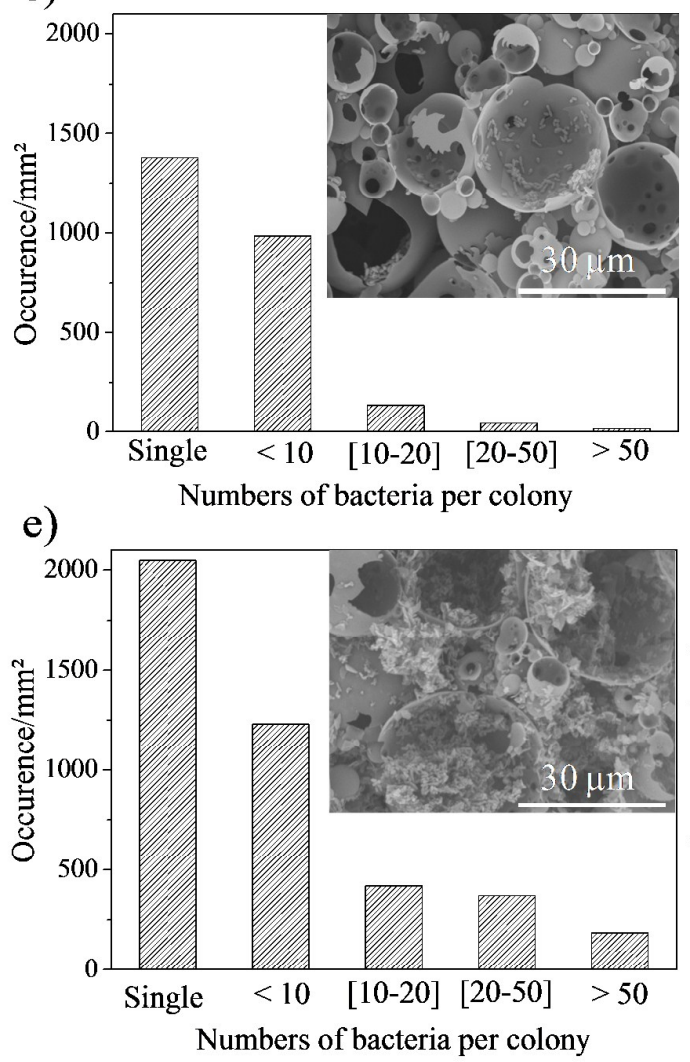

b)

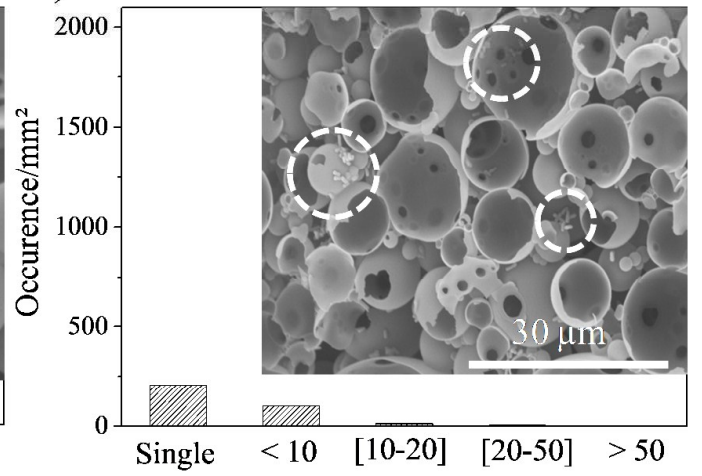

d)

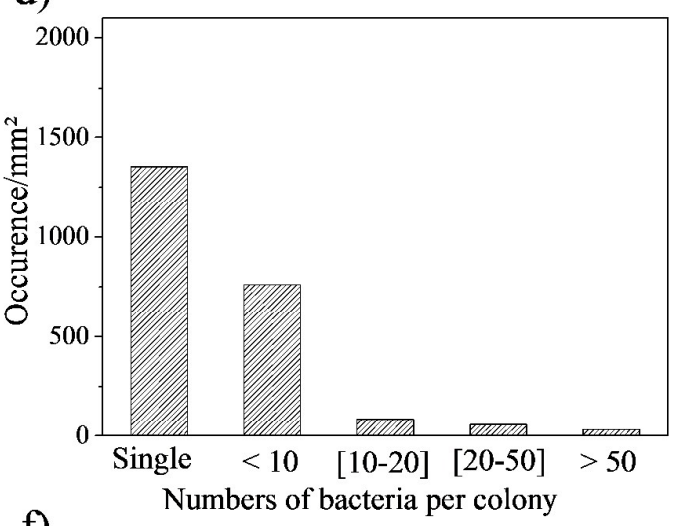

f)

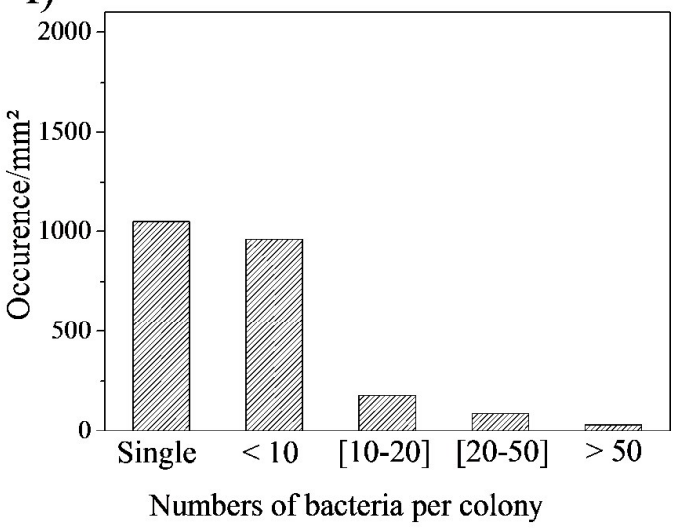

Figure 13. Distribution of bacterial populations observed though SEM at different times. A minimum of $2 \mathrm{~mm}^{2}$ of the E. coli@Si(HIPE) have been scanned to address the distributions of bacterial populations. a) 3hours b) 6hours c) 1 day d) 2 days e) 3 days f) 4 days. Embedded images correspond to SEM pictures to visualize the evolution of the bacterial density of 
populations with time. The white arrow (a) indicates a bacteria under division, while dashed circles (b) define zones bearing low density of bacterial populations in the first hours of the experiment.

As already observed with previous experiments, at the first day of growth the colonies are already established within the whole $\mathrm{Si}(\mathrm{HIPE})$ host (Fig. 13c, embedded). Some macroscopic voids are rapidly bearing colonies with more than 50 bacteria (Fig.13c). Within the following days, the growth of bacterial colonies continues and at the third day the host is completely full of bacteria presenting a very high population density, with colonies covering the Si(HIPE) macrocellular walls (Figure 13e, embedded). At the fourth day the occurrences of big colonies, medium and single bacteria seem to decrease (Fig. 13f). This diminution of bacterial growth is unexpected in regard of the previous experiments. Given the inhomogeneities in the material's porosity, leading to inhomogeneities in bacterial densities that we already discussed, there is a distinct possibility that the area observed in this experiment suffered from a decrease in population, maybe due to poor nutrients diffusion in this area of the material, while the colonies in the rest of the porous host kept growing as we observed in previous experiments. Considering the proliferation of colonies bearing the higher population densities, observed at the microscopic length scale via SEM, we can say that the growth scheme is the same than the one observed through confocal microscopy : the established colonies are growing day by day until reaching a saturation plateau. SEM investigations also confirm the hypothesis that, from these big bacterial colonies, numerous single bacteria (Figure 13) leave to other adjacent pores and establish new colonies which leads to the occupation of the whole host.

\section{Conclusions}

We have studied for the first time the fundamentals of E. coli proliferation modes within Si(HIPE) inorganic macrocellular foams at various length scales. We first shown both 
qualitatively and semi-quantitatively that the bacterial proliferation within the foam is not homogeneous, certainly induced by the random repartition of the macroscopic voids within the whole monolith, the porosity regulates thus the geometry of the bacterial proliferation whatever the micro-, meso- and macroscopic length scales studied. Particularly, bacterial proliferation occurs preferentially at the macrocellular walls' surface rather than into the cellular free volume. Macroscopically, when inoculated we found out that the bacterial growth is strengthened within the Si(HIPE) matrices, while the kinetic of bacterial growth and associated concentration at saturation is roughly $100 \%$ times higher in the case of the Si(HIPE) host compared to the traditional surrounding LB medium. When the Si(HIPE) is immerged into a LB medium where bacterial colonies are already under their phase of exponential growth, and despite the $\mathrm{Si}(\mathrm{HIPE})$ porous-based tortuosity, there is practically no difference of bacterial colonies growth between the Si(HIPE) and the surrounding LB medium, which shows the favorable environment provided by the $\mathrm{Si}$ (HIPE) host acting as a confinement medium for bacterial proliferation. In a configuration free of nutrients, we have shown that the bacterial movement is occurring through an infiltration wave, the maximum of this propagation wave moving at a constant speed of $88 \mu \mathrm{m} \mathrm{h}^{-1}$, while bacterial concentrations within the $\mathrm{Si}$ (HIPE) reach levels far above the ones reached in the presence of nutrients suggesting a real synergetic relation between the bacterial colony guests and the Si(HIPE) host. When offering or not a nutrients on one side of a Si(HIPE) rod we also showed that the bacterial proliferation modes are totally different. When there is no nutrients reservoir the proliferation is almost negligible, while when a nutrients reservoir is present the whole bacterial proliferation mode is associated to a coalescence process between the growing colonies that were rapidly established within the first hours. When the $\operatorname{Si}(\mathrm{HIPE})$ is fully colonized we found a specific distance between adjacent colonies of 5 to $15 \mu \mathrm{m}$ in good 
correspondence with the repartition of the $\mathrm{Si}$ (HIPE) wall to wall distances of the macroscopic cells.

All the results found in here are showing that the Si(HIPE) are outstanding candidates for bacterial proliferation without motion restriction occurring for instance in conventional gels. We are now studying their segregation under a restrained geometry of $\mathrm{Si}(\mathrm{HIPE})$ to optimize their activity toward the production of specific molecules, these results will be published in due course

Acknowledgments. We would like to thank Hélène Feracci and Audrey Belloc for their help when starting the bio-engineering investigations. We would also like to thank Catherine Blanco-Soulas (Zeiss Instruments), for allowing us to freely use the stereomicroscope used in acquiring the Figure 2.

\section{Reference}

1 E. Michelini and A. Roda, Anal. Bioanal. Chem., 2012, 402,1785-1797.

2 F. Lagarde and N. Jaffrezic-Renault, Anal. Bioanal. Chem., 2011, 400, 947-964.

3 D. Fiedler, U. Hager, H. Franke, U. Soltmann and H. Bottcher, J. Mater. Chem., 2007, 17, 261-266.

4 D. A. Avnir, T. Coradin, O. Lev and J. Livage, J. Mater. Chem, 2006, 16, 1013-1030.

5 M. Blondeau and T. Coradin, J. Mater. Chem., 2012, 22, 22335-22343.

6 A. Léonard, P. Dandoy, E. Danloy, G. Leroux, C. F. Meunier, J. C. Rooke, B.-L. Su, Chem. Soc. Rev. , 2011, 40, 860-885.

7 B. C. Kim and M. G. Bu, Bisosens. Bioelectron., 2003, 18, 1015-1021.

8 J. R. Premkumar, R. Rosen, S. Belkin and O. Lev, Anal. Chim. Acta, 2002, 462, 11-23.

9 J. R. Premkumar, E. Sagi, R. Rozen, S. Belkin, A. D. Modestow and O. Lev, Chem. Mater. 2002, 14, 2676-2686.

10 A. Coiffier, T. Coradin, C. Roux, O. M. M. Bouvet and J. Livage, J. Mater. Chem., 2001, 11, 2039-2044.

11 T. Coradin, and J. Livage, Acc. Chem. Res., 2007, 40, 819-826.

12 N. Nassif, O. Bouvet, M.-N. Rager, C. Roux, T. Coradin, J. Livag Mater., 2002, 1, 42-44. 
13 N. Nassif, C. Roux, T. Coradin, O.M.M. Bouvet, J. Livage J. Mater. Chem., 2003, 13, 203208.

14 N. Nassif, A. Coiffier, T. Coradin, C. Roux, J. Livage J, J. Sol-Gel Sci. Technol., 2003, 26, 1141-1144.

15 C. F. Meunier, P.Van Cutsem, Y.-U. Kwon, B.-L Su, J. Mater. Chem., 2009, 19, $1535-$ 1542 .

16 C. F. Meunier, J. C. Rooke, K. Hajdu, P.Van Cutsem, P. Cambier, A. Léonard, B.-L. Su, Langmuir, 2010, 26, 6568-6575.

17 C. F. Meunier, J. C. Rooke, A. Léonard, P. Van Cutsem, and B.-L. Su, J. Mater. Chem., 2010, 20, 929-936.

18 J. C. Rooke, A. Léonard, H. Sarmento, J.-P. Descy and B.-L. Su, J. Mater. Chem., 2008, 18, 2833-2841.

19 J. L. Connell, E. T. Ritschdorff, M. Whiteley, J. B. Shear, Proc. Natl. Acad. Sci., 2013, 110, $18380-1885$.

20 J. C. Harper, S. M. Brozik, C. J. Brinker, B. Kaehr, Anal. Chem., 2012, 84, 8985-8989.

21 J. Q. Boedicker, M. E.Vincent and R. F. Ismagilov, Angew. Chem. Int. Ed., 2009, 48, 5908-5911.

${ }^{22}$ P. Hodge, D. C. Sherrington, (Eds D. C. Sherrington, P. Hodge) Polymer-Supported Reactions in Organic Synthesis, John Wiley and Sons, Chichester, UK, 1980.

23 M. S. Silverstein, Progress in Polymer Science, 39, 2014, 199-234.

24 A. Imhof, D. J. Pine, Chem. Eng. Technol. 1998, 21, 682-685.

${ }^{25}$ F. Carn, A. Colin, M. F. Achard, H. Deleuze, E. Sellier, M. Birot, R. Backov, J .Mater. Chem., 2004, 14, 1370-1376.

${ }^{26}$ S. Ungureanu, M. Birot, G. Laurent, H. Deleuze, O. Babot, B. Julian-Lopez, M. F. Achard, M. I. Popa, C. Sanchez, R. Backov, Chem. Mater., 2007, 19, 5786-5796.

27 S. Ungureanu, H. Deleuze, C. Sanchez, M. I. Popa, R. Backov, Chem. Mater., 2008, 20, 6494-6500.

${ }^{28}$ M. Destribats, B. Faure, M. Birot, O. Babot, V. Schmitt and R. Backov. Adv. Funct. Mater. 2012, 22, 2642-2654.

29 J. Männik, R. Driessen, P. Galajda, J. E. Keymer, and C. Dekker, Proc. Natl. Acad. Sci. U. S. A., 2009, 106, 14861-14866.

${ }^{30}$ N. Brun, A.Babeau-Garcia, M.-F. Achard, C. Sanchez, F. Durand, L. Guillaume, M. Birot, H. Deleuze, R. Backov, Energy § Environmental Science, 2011, 4, 2840-2844. 
${ }^{31}$ N. Brun, A. Babeau-Garcia, H. Deleuze, F. Duran, C. Sanchez, V. Ostreicher, R. Backov, Chem. Mater.,2010, 22, 4555-4562.

32 N. Brun, S. Ungureanu, H. Deleuze, R. Backov, Chem. Soc. Rev., 2011, 40, 771-788.

33 K. D Young, Microbiol. Mol. Biol. Rev., 2006, 70, 660-703.

34 J. Saragosti, P.Silberzan, A. Buguin, PLoS ONE, 2010, 7, 4, e35412.

35 J. Saragosti, V.Calvez, N. Bournaveas, A. Buguin, P. Silberzan, B. Perthame, PLoS Comput. Biol., 2010, 6, e1000890.

36 J. Saragosti, V. Calvez, N. Bournaveas, B. Perthame, A. Buguin, P. Silberzan, Proc. Natl. Acad. Sci. U. S. A., 2011, 108, 16235-16240.

37 G. Sezonov, D. Joseleau-Petit, R. D’Ari, J. Bacteriol., 2007, 189, 8746-8749. 